\title{
AVALIAÇÃO DE PARÂMETROS AGRONÔMICOS DA CULTURA SOJA EM RESPOSTA A DIFERENTES DOSES DE ADUBAÇÃO POTÁSSICA
}

Vitor Antigo ${ }^{1}$, Raíssa Fernanda Matias ${ }^{2}$, Graciene de Souza Bido ${ }^{3}$, Daniele Fernanda Felipe $^{3}$, Anny Rosi Mannigel ${ }^{3}$

${ }^{1}$ Engenheiro Agrônomo/Centro Universitário de Maringá - UNICESUMAR, MaringáPR

${ }^{2}$ Mestranda em Segurança Alimentar/Centro Universitário de Maringá UNICESUMAR, Maringá-PR

${ }^{3}$ Professora Doutora do Programa de Mestrado em Ciência, Tecnologia e Segurança Alimentar do Centro Universitário de Maringá - UNICESUMAR, Maringá-PR.

Pesquisadora do Instituto Cesumar de Ciência, Tecnologia e Inovação. Bolsista

Produtividade em Pesquisa do ICETI

E-mail de contato: (armannigel@gmail.com)

Recebido em: 15/05/2020 - Aprovado em: 15/06/2020 - Publicado em: 30/06/2020

DOI: 10.18677/EnciBio_2020B9

\section{RESUMO}

A soja é uma cultura consumida em todos os continentes do mundo e principalmente pelos subprodutos dos grãos, que são considerados ricos em óleo e proteína. $O$ Brasil é o segundo maior produtor mundial, com uma área plantada de 35,9 milhões de hectares e produção estimada em 115 milhões de toneladas de grãos. Novas pesquisas têm sido necessárias para otimizar sua cadeia produtiva, afim de reduzir custos e proporcionar aos agricultores incremento de rendimentos. Dentre estas, a adubação potássica se destaca na cultura da soja, devido ao fato de que o potássio é considerado o segundo elemento mais extraído pela planta. Diante da necessidade de maiores estudos para proporcionar o incremento produtivo na cultura da soja e atender a demanda global por este produto, e levando em consideração a lucratividade do produtor e a utilização de adubação potássica, este artigo tem como objetivo avaliar componentes biométricos da cultura da soja em diferentes dosagens de adubação de potássio. O experimento foi desenvolvido no delineamento de blocos completos com tratamentos ao acaso, sendo um total de quatro tratamentos e quatro repetições, totalizando 16 parcelas de $25 \mathrm{~m}^{2}$ cada. Concluiu-se através desta pesquisa que a adubação potássica corresponde significativamente para o desenvolvimento da cultura da soja, proporcionando o aumento das variáveis produtividade, altura e massa seca aérea. Além disso, quando disponibilizado potássio, juntamente com outros macronutrientes, como fosforo e nitrogênio, o desenvolvimento da planta foi ainda melhor.

PALAVRAS-CHAVE: Adubação mineral; Potássio; Produtividade. 


\title{
EVALUATION OF AGRONOMIC PARAMETERS OF SOYBEAN CULTURE IN RESPONSE TO DIFFERENT DOSES OF POTASSIUM FERTILIZATION
}

\begin{abstract}
Soy is a crop consumed on all the continents of the world and mainly for the byproducts of grains, which are considered rich in oil and protein. Brazil is the second largest producer in the world, with a planted area of 35.9 million hectares and production estimated at 115 million tons of grain. New research has been necessary to improve its production chain, in order to reduce costs and provide farmers with increased incomes. Among these, potassium fertilization stands out in soybean culture, due to the fact that potassium is considered the second element most extracted by the plant. In view of the need for further studies to provide a productive increase in soybean culture and meet the global demand for this product, and taking into account the profitability of the producer and the use of potassium fertilizer, this article aims to evaluate biometric components of the crop in different potassium fertilization dosages. The experiment was developed in a complete block design with randomized treatments, with a total of four treatments and four repetitions, totaling 16 plots of $25 \mathrm{~m}^{2}$ each. It is concluded through this research that the potassium fertilization corresponds significantly for the development of the soybean culture, providing the increase of the variables productivity, height and dry mass area. In addition, when potassium was made available, along with other macronutrients, such as phosphorus and nitrogen, the plant's development was even better.
\end{abstract}

KEYWORDS: Mineral fertilization; Potassium; Productivity

\section{INTRODUÇÃO}

A soja (Glycine max L.) é uma cultura consumida em todos os continentes do mundo e principalmente pelos subprodutos dos grãos, que são considerados ricos em óleo e proteína (FARIA et al., 2018). O Brasil é o segundo maior produtor mundial, com uma área plantada de 35,9 milhões de hectares, produção estimada em 115 milhões de toneladas de grãos (CONAB, 2019) e apresenta produtividade média de $3.074 \mathrm{~kg} \mathrm{ha}^{-1}$ (ZUFFO et al., 2019).

A soja é amplamente utilizada para a preparação de rações animais, produção de óleo e outros subprodutos, além disso, o seu consumo in natura tem se ampliado nos dias atuais (LEMES et al., 2019).

Conforme Bossolani et al. (2018) são frequentes as pesquisas sobre aplicação e formas de adubos, principalmente para reduzir perdas e aumentar a eficiência na agricultura. Sediyama (2016) ressalta que um dos mais relevantes fatores limitantes da produção é o manejo inadequado dos nutrientes. $E$, uma das principais maneiras utilizadas para ocasionar o incremento produtivo é através da adubação mineral, e dentre esta, a adubação potássica se destaca na cultura da soja, Um dos principais elementos químicos exigidos pela soja é o potássio $(\mathrm{K})$, encontrado em baixas concentrações nos solos tropicais brasileiros, mas com efeito direto no rendimento de grãos, proteínas e óleos (LIMA et al., 2017).

Em caráter fisiológico, as principais funções do potássio estão ligadas a ativação de sistemas enzimáticos relacionados ao processo de respiração e fotossíntese (TAIZ et al., 2017). Além disso, a concentração de potássio em uma planta está intimamente ligada à abertura e fechamento dos estômatos (NOVAIS et al., 2007).

A adubação potássica é fundamental, não apenas para que haja incremento de produtividade, como também no manejo da sanidade em diversas culturas 
(GABRIEL et al., 2016). Resultados obtidos por Balardin et al. (2006), evidenciam na cultura da soja a influência do potássio sobre a redução da severidade e a taxa de progresso da ferrugem asiática, causada pelo fungo Phakopsora pachyrhizi.

Outro benefício da realização desta adubação está relacionada à tolerância a estresses abióticos, estudos demonstram que a adubação potássica contribuiu para a tolerância ao frio em cultivo de canola (MENDONÇA et al., 2016).

O elemento potássio apresenta relevância fundamental para o crescimento e o metabolismo das plantas, pois é o ativador de mais de meia centena de reações enzimáticas (BORIN et al., 2017). A deficiência deste nutriente causa clorose internerval, seguida de necrose nos bordos e ápice das folhas velhas, devido à formação de putrescina. Lavoura com esta deficiência, além da redução do rendimento, produz grãos pequenos, enrugados e deformados com baixo vigor e baixo poder germinativo, a maturação da planta toda é atrasada, podendo causar também, a haste verde, retenção foliar e vagens chochas (SFREDO; BORKET, 2004).

Em relação a lucratividade da cultura, o lucro líquido é definido como o rendimento real da propriedade, ou seja, o excedente financeiro após cobrir os gastos referentes ao custo de produção. Um dos principais fatores relacionados a lucratividade é o custo de produção, que é definido como o custo direto para se produzir. Dentre os custos de produção, os relatórios da CONAB (2020) demonstram que os custos com fertilizantes representam $22 \%$ do custo total estimado para a cultura da soja.

Diante da necessidade de maiores estudos para proporcionar o incremento produtivo na cultura da soja e atender a demanda global por este produto, e levando em consideração a lucratividade do produtor e a utilização de adubação potássica, este artigo tem como objetivo avaliar componentes biométricos da cultura da soja em diferentes dosagens de adubação de potássio.

\section{MATERIAL E MÉTODOS}

O experimento foi realizado entre os meses de outubro de 2019 e março de 2020 no município de Marialva-PR (2327'49,86"S, 5147'18,74" oeste, elevação de $614 \mathrm{~m}$ ). O clima predominante na região é do tipo Cfa, com temperaturas medias de $22^{\circ} \mathrm{C}$ e média pluviométrica em torno de $1500 \mathrm{~mm}$ anuais (IAPAR, 2019). Em relação ao solo preponderante na região, o mesmo apresenta a seguinte classificação: LATOSSOLO Vermelho distrófico, com 200, 200 e $600 \mathrm{~g} \mathrm{~kg}^{-1}$ de areia, silte e argila, respectivamente (SANTOS et al., 2018).

Para realização do experimento foi utilizado a cultivar Valente, da empresa Brasmax, com espaçamento de $0,50 \mathrm{~cm}$ entre linhas e 13 sementes por metro linear. O experimento foi desenvolvido no delineamento de blocos completos com tratamentos ao acaso, sendo um total de quatro tratamentos e quatro repetições, totalizando 16 parcelas de $25 \mathrm{~m}^{2}$ cada.

Os tratamentos estudados foram:

T1: Testemunha $\left(0,0 \mathrm{~kg} \mathrm{ha}^{-1}\right.$ de $\left.\mathrm{K}_{2} \mathrm{O}\right)$;

T2: $312,5 \mathrm{~kg} \mathrm{ha}^{-1}$ de formulado $2-20-18$ fornecendo $56,25 \mathrm{~kg} \mathrm{ha}^{-1}$ de $\mathrm{K}_{2} \mathrm{O}$ no plantio;

T3: $312,5 \mathrm{~kg} \mathrm{ha}^{-1}$ de formulado 2-20-18 fornecendo $56,25 \mathrm{~kg} \mathrm{ha}^{-1}$ de $\mathrm{K}_{2} \mathrm{O}$ no plantio + $125 \mathrm{~kg} \mathrm{ha}^{-1}$ de $\mathrm{KCL}$ fornecendo $75 \mathrm{~kg} \mathrm{ha}^{-1}$ lanço

T4: $125 \mathrm{~kg} \mathrm{ha}^{-1}$ de de KCL fornecendo $75 \mathrm{~kg} \mathrm{ha}^{-1}$ lanço. 
Com base na metodologia estabelecida por Benincasa (1988), foram analisados os seguintes parâmetros biométricos:

Altura: A altura da planta foi determinada medindo-se em metros, a distância do colo da planta até o ápice caulinar.

Matéria seca: Determinada como sendo o peso de raiz, caule e folhas após a permanência em estufa por 48 horas, na temperatura de 85-95 Graus Celsius.

Produtividade: Determinada como sendo o peso dos grãos colhidos de cada tratamento, após debulha das plantas.

Peso de mil grãos: Foi contabilizado o número de mil grãos e pesado o mesmo em triplicada na balança de precisão.

Após a coleta de dados, os pressupostos foram verificados e depois de atendidos, foi realizada a análise de variância (supondo efeito fixo) e o teste de Scott Knott, com probabilidade de $5 \%$ para avaliação dos tratamentos e das respectivas variáveis respostas analisadas. As análises foram realizadas através do programa estatístico SISVAR (FERREIRA, 2020).

\section{RESULTADOS E DISCUSSÃO}

A análise de variância apresentada na Tabela 1 demonstrou que a utilização da adubação potássica na cultura da soja proporcionou diferença significativa para as variáveis produtividade, massa seca da parte aérea e altura, enquanto que não obteve diferença significativa para as variáveis peso de mil grãos e massa seca da parte radicular.

TABELA 1. Análise de variância para Peso de mil grãos (PMG), Massa seca da parte aérea (MSPA), Altura (ALT), Produtividade (PROD) e Massa seca da raiz (MSR) na cultura da soja mediante diferentes dosagens de adubação potássica

\begin{tabular}{l|l|l|l|l|l|l}
\hline FV & GL & QM (PMG) & QM (MSPA) & QM (ALT) & $\begin{array}{l}\text { QM } \\
(\text { PROD) }\end{array}$ & $\begin{array}{l}\text { QM } \\
(\text { MSR })\end{array}$ \\
\hline Tratamentos & 3 & $189,8958^{\text {ns }}$ & $204,555^{* *}$ & $798,915^{\star *}$ & $3050,398^{* *}$ & $12,915^{\text {ns }}$ \\
Erro & 12 & 110,7291 & 37,8333 & 54,25 & 59,1458 & 5,25 \\
Média & & 181,8125 & 71 & 72,875 & 131,9375 & 13,375 \\
CV \% & & 5,79 & 8,55 & 11 & 5,3 & 17,13 \\
Pr $>$ Fc & & 0,2159 & 0,0138 & 0,0005 & 0,0001 & 0,1128 \\
& & & & & & \\
\hline
\end{tabular}

** significativo ao nível de $1 \%$ de probabilidade; * significativo ao nível de $5 \%$ de probabilidade, ns: não significativo ao nível de $5 \%$ de probabilidade pelo teste $\mathrm{F}$. FV: Fonte de Variação; GL: grau de liberdade; QM: quadrado médio; CV: coeficiente de variação; Pr>Fc: P-valor.

Em relação a matéria seca da raiz das plantas de soja, não houve diferença significativa entre os tratamentos analisados e a testemunha, contrariando os dados encontrados por KAWAVATA et al. (2017), nos quais o aumento na dose de potássio causou redução na massa seca das raízes de milho.

Outra variável que não apresentou diferença significativa mediante diferentes dosagens de adubação potássica foi o peso de mil grãos, apesar de a adubação potássica ser responsável pelo melhor enchimento do grão. A nutrição de potássio tem partição no acumulo de carboidratos e na translocação de nutrientes via sistema vascular (CAKMAK et al., 1994), o que pode influenciar diretamente na quantidade destes para o enchimento dos grãos. Resultados semelhantes foram encontrados 
por Cavalini et al. (2018) ao estudarem o parcelamento da aplicação de potássio à cultura da soja.

Ainda analisando a Tabela 1, no que se refere a variável altura, massa seca da parte área e produtividade, estas variáveis apresentaram diferença significativa mediante o fornecimento de potássio, quando comparado com a testemunha. Tais resultados podem ser creditados ao fato de que o $\mathrm{K}$ influencia alguns processos metábolicos da planta, como por exemplo a fotossíntese e a translocação de fotoassimilados (JÚLIO et al., 2016). Sobre concentração adequada de potássio nas plantas, levando em consideração que este nutriente regula a abertura e fechamento estomático e que este por sua vez este ligado ao processo fotossintético, o fornecimento de potássio estimula uma melhor produção de fotoassimilados pela planta e consequentemente melhor desenvolvimento vegetativo e reprodutivo no vegetal (NOVAIS et al., 2007).

Tais resultados também foram encontrados em outras pesquisas e outras culturas, como por exemplo em Sampaio et al. (2016), que demonstraram a importância do potássio sobre o crescimento de plantas de eucalipto. Em relação ao desenvolvimento da cultura da soja, os resultados estão dispostos na Tabela 2.

TABELA 2. Teste de Scott Knott para comparação de médias para as variáveis Produtividade (PROD), Massa seca da parte aérea (MSPA) e Altura de planta (AP) mediante diferentes dosagens de adubação potássica

\begin{tabular}{c|l|l|l}
\hline Tratamentos & PROD $\left(\mathrm{kg} \mathrm{ha}^{-1}\right)$ & MSPA $(\mathrm{g})$ & AP $(\mathrm{cm})$ \\
\hline T1 & $2.400 \mathrm{~d}$ & $62,0 \mathrm{~b}$ & $69,5 \mathrm{~b}$ \\
T2 & $3.625 \mathrm{~b}$ & $69,0 \mathrm{~b}$ & $72,0 \mathrm{~b}$ \\
T3 & $4.133 \mathrm{a}$ & $78,5 \mathrm{a}$ & $92,0 \mathrm{a}$ \\
T4 & $3.150 \mathrm{c}$ & $74,5 \mathrm{a}$ & $58,0 \mathrm{c}$ \\
\hline
\end{tabular}

*Médias seguidas pelas mesmas letras não diferem entre sim pelo teste de Scott Knott a 5\% de probabilidade

Os valores de produtividade de soja para os tratamentos que receberam $\mathrm{K}_{2} \mathrm{O}$ se encontram próximos e superiores aos das medias de produtividade paranaense (3.473 kg ha $\mathrm{kg}^{-1}$ ) e brasileira (3.271 $\mathrm{kg} \mathrm{ha}^{-1}$ ) conforme dados disponibilizados pela CONAB (2019). A maior produtividade de soja no tratamento T2 e T3 é resultado da disponibilização de $\mathrm{K}$ ocasionada pela aplicação de $\mathrm{K}_{2} \mathrm{O}$ no plantio nos dois tratamentos. Foloni e Rosolem (2008) também encontraram respostas significativas à adubação potássica na cultura da soja quando testaram diferentes doses de $\mathrm{K}_{2} \mathrm{O}$.

A produtividade superior dos tratamentos 2 e 3 em relação ao tratamento 4, pode ser explicada pela fonte de adubo utilizada, nos tratamentos 2 e 3 foi utilizado um formulado que, juntamente com potássio, também forneceu nitrogênio e fosforo, o que proporcionou melhor desenvolvimento pra planta e influenciou na produtividade final. Enquanto que no tratamento 4, o adubo utilizado foi o cloreto de potássio que continha $60 \%$ de $\mathrm{K}_{2} \mathrm{O}$ em sua formulação, sem adição de nitrogênio e fosforo.

A aplicação de potássio no plantio exerceu maior influência positiva do que a aplicação a lanço, possivelmente, a aplicação de potássio a lanço pode ter sofrido o processo de lixiviação, o que colaborou para a resposta apresentada no trabalho. Outros autores como Werle et al. (2008), também enfatizaram que a adubação potássica a lanço sofre efeito da lixiviação através da carreação do nutriente pela água da chuva em superfície. 
Em relação a variável resposta da massa seca da parte aérea, os tratamentos 3 e 4 apresentaram diferença significativa em relação aos demais. Este resultado é corroborado com as conclusões obtidas em trabalhos dos pesquisadores Pereira et al. (2016) que também verificaram aumento na massa da parte aérea com o aumento de doses de potássio.

A variável altura de planta ocorreu diferença estatística entre os tratamentos, sendo que o T3 apresentou um valor mais elevado. Já o T4 teve o valor mais baixo. A influência do $\mathrm{K}$ na altura da planta está relacionada ao efeito indireto do mesmo na absorção de $\mathrm{N}$ e $\mathrm{P}$, o que resulta em maior divisão e expansão celular (PETTER et al., 2016), como para o fornecimento do tratamento 3 foi utilizado o formulado 2-2018, a disponibilidade de nitrogênio e fosforo juntamente com o potássio proporcionou melhor desenvolvimento da planta. Enquanto que no tratamento 4 que foi aplicado somente cloreto de potássio, a ausência de nitrogênio e fosforo na fase inicial de desenvolvimento para planta, proporcionou menor desenvolvimento e consequentemente menor altura.

Lana et al. (2002), também observaram que a aplicação de potássio resultou em aumento da altura de planta. A altura de planta desejável para uma colheita mais eficiente, de acordo com Sediyama (2015), é em torno de 70 a $80 \mathrm{~cm}$. Já Bertolin (2010) afirma que valores de altura de plantas de soja próximos a $85 \mathrm{~cm}$ favorecem a colheita mecânica das plantas. Os tratamentos 2 e 3 apresentaram-se próximos a estes limites.

\section{CONCLUSÕES}

Conclui-se nesta pesquisa que a adubação potássica proporcionou o aumento das características produtivas da soja, sendo então uma prática que pode ser recomendada aos produtores rurais.

Verificou-se que ocorreu um aumento de $31 \%$ da produtividade da soja quando foi realizada a adubação potássica em cobertura (T4). Além disso, quando disponibilizado potássio, juntamente com outros macronutrientes, como fosforo e nitrogênio (T2 e T3), o desenvolvimento da planta foi ainda mais expressivo, resultando em um aumento de $51 \%$ e $72 \%$ na produtividade, respectivamente.

A Massa seca da parte aérea (MSPA) sofreu influência positiva da adubação aplicada, sendo que os tratamentos T3 e T4 foram os que tiveram os resultados mais altos (26 e $20 \%$ de aumento, respectivamente).

O Tratamento T3 proporcionou a maior altura de planta (AP).

Os tratamentos estudados nesta pesquisa não tiveram influência sobre peso de mil grãos e massa seca da parte radicular.

\section{REFERÊNCIAS}

BALARDIN, R. S.; DALLAGNOL, L. J.; DIDONÉ, H.T.; NAVARINI, L. Influência do Fósforo e do Potássio na Severidade da Ferrugem da Soja Phakopsora pachyrhizi. Fitopatologia Brasileira, 31:462-467, 2006.

BERTOLIN, D.C.; SÁ, M.E.; ARF, O.; FURLANI JUNIOR, E. COLOMBO, A.S.; CARVALHO, F.L.B.M. Aumento da produtividade de soja com a aplicação de bioestimulantes. Bragantia, Campinas, v. 69, n. 2, p. 339-347, 2010

BORIN, A. L. D. C.; FERREIRA, A. C. B.; SOFIATTI, V.; CARVALHO, M. C. S; MORAES, M. C. G. Produtividade do algodoeiro adensado em segunda safra em resposta à adubação nitrogenada e potássica. Rev. Ceres, Viçosa , v. 64, n. 6, p. 
622-630,

dez.

2017

Disponível

em

<http://www.scielo.br/scielo.php?script=sci_arttext\&pid=S0034-

737X2017000600622\&lng=pt\&nrm=iso > . doi: https://doi.org/10.1590/0034-

$737 \times 201764060009$.

BOSSOLANI, J. W.; LAZARINI, E.; SOUZA, L. G. M.; PARENTE, T. L.; CAIONI, S.; BIAZI, N. Q. Potassium doses in previous crops and effect on soybean in succession. Rev. bras. eng. agríc. ambient., Campina Grande , v. 22, n. 2, p. 90 94, fev. $2018 \quad$ Disponível em <http://www.scielo.br/scielo.php?script=sci_arttext\&pid=S1415-

43662018000200090\&lng=pt\&nrm=iso >. Doi: $\quad$ https://doi.org/10.1590/18071929/agriambi.v22n2p90-94.

CAKMAK, I.; HENGELER, C.; MARSCHNER, H. Partitioning of shoot and root dry matter and carbohydrates in bean plants suffering from phosphorus, potassium and magnesium deficiency. Journal of experimental botany., 45, 1245-1250, 1994

CAVALINI, P. F.; SEVILHA, A.; CRUZ, R. M. S. da; ALBERTON, O. Resposta da soja a épocas de aplicação de potássio em cobertura. Arq. Ciênc. Vet. Zool. UNIPAR, Umuarama, v. 21, n. 1, p. 23-28, 2018.

CONAB, Acompanhamento da safra brasileira de grãos Companhia Nacional de Abastecimento. Acomp. Safra bras. grãos, v. 7 - safra 2019/20- n. 1 p. 1-114Primeiro levantamento, Brasília, 2019. Disponível em: https://www.conab.gov.br/infoagro/safras/graos

CONAB, Planilhas de Custos de Produção - Culturas de $1^{\text {a }}$ Safra Companhia Nacional de Abastecimento. Culturas de 1a Safra - Março/2019, Brasília, 2020. Disponível em: https://www.conab.gov.br/info-agro/custos-de-producao/planilhas-decusto-de-producao/itemlist/category/406-planilhas-de-custos-de-producao-culturasde-1-safra

FARIA, L. A.; PELUZIO, J. M.; SANTOS, W. F.; SOUZA, C. M.; COLOMBO, G. A.; AFFÉRRI, F. S. Oil and protein content in the grain of soybean cultivars at different sowing season. Revista Brasileira de Ciências Agrárias, v.13, n.2, e5518, Recife, 2018. Disponível em: http://www.agraria.pro.br/ojs2.4.6/index.php?journal=agraria\&page=issue\&op=view\&path\%5B\%5D=56

FERREIRA, D. F. SISVAR: A computer analysis system to fixed effects split plot type designs. Revista Brasileira de Biometria, [S.I.], v. 37, n. 4, p. 529-535, dec. 2019. ISSN 1983-0823. Available at: <http://www.biometria.ufla.br/index.php/BBJ/article/view/450>. Date accessed: 10 feb. 2020. doi: https://doi.org/10.28951/rbb.v37i4.450.

FOLONI, J. S. S.; ROSOLEM, C. A. Produtividade e acúmulo de potássio na soja em função da antecipação da adubação potássica no sistema plantio direto. Revista Brasileira de Ciência do Solo. 2008, vol.32, n.4, p. 1549-1561. . Available from: <http://www.scielo.br/scielo.php?script=sci_arttext\&pid=S0100-

06832008000400019\&Ing=en\&nrm=iso>. ISSN 1806-9657. Doi: http://dx.doi.org/10.1590/S0100-06832008000400019. 
GABRIEL, S. G.; BUENO, A. C.; SANTOS, R. F. Resposta da soja (Glycine max L.) à duas diferentes fontes de potássio. Revista UNINGÁ Review, v.25, n.1, p. 5-9, Paraná, 2016. Disponível em: http://34.233.57.254/index.php/uningareviews/article/view/1749

IAPAR-Instituto Agronômico do Paraná. Cartas climáticas básicas do Estado do Paraná. Londrina: lapar, 2019. Disponível em: http://www.iapar.br/pagina-677.html

JÚLIO, O. L. L.; ASCARI, J. P.; MENDES, I. R. N.; SANTOS, E. S.; NIED, A. H. Formas de adubação potássica e produtividade da cultura da soja. Revista Agrarian. v.9, n.32, p. 149-155, $2016 . \quad$ Disponível em: http://ojs.ufgd.edu.br/index.php/agrarian/article/view/4004/3648.

LANA, R. M. Q.; HAMAWAKI, O. T.; LIMA, L. M. L.; ZANÃO JÚNIOR, L. A. Resposta da soja a doses e modos de aplicação de potássio em solo de cerrado. Bioscience Journal, Uberlândia, v. 18, n. 2, p.17-23, 2002 . Disponível em: http://www.seer.ufu.br/index.php/biosciencejournal/issue/view/385

LEMES, E. ; ALMEIDA, A. ; JAUER, A. ; MATTOS, F. ; TUNES, L. . Tratamento de sementes industrial: potencial de armazenamento de sementes de soja tratadas. Colloquium Agrariae (UNOESTE), v. 15, p. 94-103, 2019. Disponível em: <http://dx.doi.org/ 10.5747/ca.2019.v15.n3.a302

LIMA, M. D. ; PELUZIO, J. ; MANDARINO, J. M. G.; LIMA, D. Potassium fertilization and sowing seasons on protein yield in soybean cultivars. Revista Brasileira de Engenharia Agricola e Ambiental, v. 21, p. 392-397, 2017. Doi: http://dx.doi.org/10.1590/1807-1929/agriambi.v21n6p392-397

MENDONÇA, J. A.; RIBOLDI, L. B.; SOARES, C. D. F.; CASTRO, P. R. C.; KLUGE, R. A. Canola (Brassica napus L.) ESALQ. Série Produtor Rural, no61, 32p.il. Piracicaba, 2016.

NOVAIS, R. F.; ALVAREZ, V. V. H.; BARROS, N. F.; FONTES, R. L. F.; CANTARUTTI, R. B.; NEVES, J. C. L. (eds). Fertilidade do Solo, SBCS/UFV, p. 92132, Viçosa, 2007.

PEREIRA, C. S.; FREITAS, A. A. ; CHAPLA, M. V. ; LANGE, A. . Doses de potássio com a presença de enxofre na cultura da soja. Global Science and Technology, v. 9, p. 22-32, 2016. Disponível em: https://rv.ifgoiano.edu.br/periodicos/index.php/gst/issue/view/29

PETTER, F. A.; Andrade, F.R. ; ZUFFO, A. M. ; MONTEIRO, M. M. S. ; PACHECO, L. P. ; ALMEIDA, F. A. . Doses e épocas de aplicação de potássio no desempenho agronômico do milho no cerrado piauiense. Comunicata Scientiae (Online), v. 7, p. 372, 2016. Disponível em: https://dialnet.unirioja.es/servlet/revista?codigo=15576

SAMPAIO, T. F.; DALCIN, T. E. ; BOGIANI, J. C. ; MORI, E. S. ; GUERRINI, I. A. Selection of eucalyptus clones and adjustment of potassium doses for extended drought in Bahia savanna. Rev. Árvore, Viçosa, v. 40, n. 6, p. 1031-1039, Dec. 2016. Disponível em: 
<http://www.scielo.br/scielo.php?script=sci_arttext\&pid=S0100-

67622016000601031\&Ing=en\&nrm=iso>. Doi: https://doi.org/10.1590/010067622016000600008

SANTOS, H. G.; JACOMINE, P. K. T; ANJOS, L. H. C.; OLIVEIRA, V. A.; LUMBREBAS, J. F.; COELHO, M. R.; ALMEIDA, J. A.; ARAUJO, J. C.; OLIVEIRA, J. B.; CUNHA, T. J. F. Sistema Brasileiro de Classificação de Solos, Embrapa, 5 ed, 2018.

SEDIYAMA, T. Melhoramento genético da soja. Londrina: Mecenas. 2015. 252p.

SEDIYAMA, T. Produtividade da soja. Ed. 1, Mecenas, Londrina. 2016, 310 p.

SFREDO, G. J.; BORKERT, C. M. Deficiências e Toxicidades de Nutrientes em Plantas de soja. Embrapa, documento 231, 2004.

TAIZ, L.; ZEIGER, E.; MOLLER, I.; MURPHY, A. Fisiologia e desenvolvimento vegetal. 6.ed. Porto Alegre: Artmed, 2017. 888 p.

KAWAVATA, C. K. H.; FOIS, D. A.F.; COPPO, J. C.; ALVES NETO, A. Influência de doses e de duas fontes de potássio no sistema radicular do milho e na condutividade elétrica no solo. Investig. Agrar. [online]. 2017, vol.19, n.1, pp.28-34. Disponível em: <http://scielo.iics.una.py/scielo.php?script=sci_arttext\&pid=S2305-

06832017000100028\&lng=es\&nrm=iso $>$. ISSN 2305-0683.

Doi: http://dx.doi.org/10.18004/investig.agrar.2017.junio.28-34.

WERLE R., GARCIA R. A., ROSOLEM C. A. Lixiviação de potássio em função da textura e da disponibilidade do nutriente no solo, Revista Brasileira Ciência do Solo, v.32, n.6, 2008. Disponível em: https://www.scielo.br/pdf/rbcs/v32n6/v32n6a09.pdf

ZUFFO, A.M.; STEINER, F. ; BUSH, A. ; SANTOS, D. M. S. . Adubação nitrogenada na soja inibe a nodulação e não melhora o crescimento inicial das plantas. RAMA Revista em Agronegócio e Meio Ambiente, v. 12, p. 333-349, 2019. . Disponível em: <http://dx.doi.org/10.17765/2176-9168.2019v12n2p333-349 